Un análisis de la energía emocional en catas de vino

(Ciudad de Buenos Aires, Argentina)

An analysis of emotional energy in wine tastings

(Buenos Aires City. Argentina)

Mariana Palumbo

Instituto Interdisciplinario de Estudios de Género (IIEGE-UBA/CONICET), Buenos Aires, Argentina, email: mrnpalumbo@gmail.com

\title{
Resumen:
}

En este artículo describo y analizo, desde un abordaje cualitativo, el aumento de la energía emocional —bajo los términos de Randall Collins - durante la interacción que tiene lugar en catas de vino desarrolladas en la Ciudad de Buenos Aires (Argentina). Estos eventos son un ámbito donde mujeres y varones cis heterosexuales, adultos/as, sin pareja y de sectores medios concurren para sociabilizar erótica y/o afectivamente. Las situaciones de interacción donde la energía emocional aumenta se registra luego de la tercera copa, a partir de la cual se observa un corrimiento del umbral de desinhibición.

Palabras claves: energía emocional; catas de vino; interacciones; sociabilizar

CÓMO CITAR: Palumbo, M. (2018). Un análisis de la energía emocional en catas de vino (Ciudad de Buenos Aires, Argentina). Revista Interdisciplinaria de Estudios de Género de El Colegio de México, 4, 30 de julio de 2018, e266, http://dx.doi.org/10.24201/eg.v4i0.266 


\begin{abstract}
:
This article describes and analyses the increase of emotional energy -in terms of Randall Collins - in situations of interaction that happen in wine tastings, situated in Buenos Aires City (Argentina), from a qualitative approach. These events are scenes where cis heterosexual, adults, single and middle-class women and men concur for erotic and/or affectively socialize. The interactions where emotional energy increases happen after the third glass of wine, when we can notice that people are more disinhibited.
\end{abstract}

Key words: emotional energy; wine tastings; interactions; socialize

\title{
Introducción
}

En el contexto de modernidad tardía (Illouz, 2009) las trayectorias de los sujetos devienen heterogéneas y zigzagueantes. Las personas transitan por diferentes vínculos o parejas a lo largo de su vida y conforman lazos que se adecuan a sus expectativas individuales (Lipovetsky, 2000, p.78).

Un elemento que aparece en este estado de la modernidad son las soluciones de mercado, las cuales ocupan un lugar central. Dentro de éstas se halla la mercantilización de lo afectivo, a partir de la compra y venta de servicios diseñados para los ámbitos emocionales de nuestras vidas, entre ellos los de búsqueda de pareja y vínculos eróticos. Estamos ante lo que la bibliografía especializada considera una mercantilización de la vida íntima ${ }^{1}$ (Elizalde y Felitti, 2015; Guerra, 2016; Gregori, 2011; Haack y Falcke, 2014; Hakim, 2012; Hochschild, Illouz, 2007, 2012; Piscitelli, 2009, 2011). Dentro de esta mercantilización y en un contexto de mayor autonomía femenina, las mujeres

\footnotetext{
${ }^{1}$ Existe una vasta bibliografía que problematiza estas cuestiones a partir del análisis del mercado sexual: Agustín (2005), Da Silva y Blanchette (2005), Gregori (2011), Guerra (2016), Heineman, MacFarlane y Brents (2012), Pruitt (1995), Piscitelli (2009, 2011, 2014), Satz (2015).
} 
aparecen como activas consumidoras del mercado $^{2}$ sexual y afectivo. Hay una amplia oferta de bienes y servicios, como coaching (entrenamiento) sexual, libros, revistas y películas consagradas al erotismo y a la "sexualización" femenina (Elizalde y Felitti, 2015, p. 6).

Los espacios sociales destinados a la configuración de mercados eróticos y/o afectivos donde tienen lugar los encuentros pueden ser tanto virtuales como cara a cara (Illouz, 2012): bares, discotecas, saunas, clases de baile, sitios virtuales de contenido sexual, sitios de citas como empresas dedicadas a la formación de parejas y catas de vino, entre otros.

En este artículo describo y analizo escenas donde se visualiza un aumento de la energía emocional (Collins, 2009), en un espacio cara a cara, durante el desarrollo de catas de vino boutique en una vinería ubicada en la Ciudad de Buenos Aires (Argentina). ${ }^{3}$ El vino puede ser analizado, desde la perspectiva interaccionista de Collins, como un emblema de membresía grupal basado en diversos ritos que incluyen desde observar su textura y olerlo, hasta estudiar el efecto que produce en las personas con las cuales se comparte la actividad de degustarlo. De esta manera, las catas se develan como un ámbito donde mujeres y varones cis $^{4}$ heterosexuales, adultos/as, ${ }^{5}$ que no están en pareja

${ }^{2}$ Los mercados son formas de organización económica y social. Permiten la competencia y la cooperación entre personas que de otro modo serían completamente desconocidas entre sí dentro de un sistema voluntario, aunque con limitaciones internas y externas, de intercambio. Por medio de los mercados los individuos pueden comunicar deseos y difundir información. Es decir, los mercados no se limitan a intercambiar o vender productos (bienes o servicios), sino que contribuyen a la conformación de nuestra política, cultura e identidad (Satz, 2015, pp. 17-20, 32).

${ }^{3}$ Este artículo se desprende de los resultados de mi tesis de doctorado en Ciencias Sociales (Universidad de Buenos Aires) denominada "Solos y solas: búsquedas de encuentros eróticos y afectivos entre mujeres y varones heterosexuales (Área Metropolitana de Buenos Aires, 2015-2017)".

${ }^{4}$ Cis es una forma de indicar a las personas que no son trans. Es decir, aquellas que se identifican con el género asignado al nacer. Los términos cis y trans oponen dos prefijos latinos. "Cis" quiere decir "de este lado", mientras que "trans" significa "del otro lado" (Blumer, Ansara y Watson, 2013). Asimismo, a partir del prefijo cis se nombra a la mayoría dominante y se explícita que las identidades no trans también son construidas (Serano, 2016).

${ }^{5}$ En relación con el grupo etario analizo al segmento de entre 35 y 50 años. En primer lugar, la concentración de los divorcios, al momento de su sentencia, está dada en los grupos de 35-39, 40-44 y 45-49 (Dirección General de Estadísticas y Censos. Gobierno de la Ciudad de Buenos Aires, 2014). En segundo lugar, a los espacios de sociabilidad 
y de sectores medios ${ }^{6}$ concurren para sociabilizar erótica y/o afectivamente. En el análisis tengo en cuenta las pautas de cortejo y emociones que circulan, las corporalidades, los escenarios de interacción (Paiva, 2006) y lo que sucede con la energía emocional de los sujetos. Las situaciones de interacción donde la energía emocional aumenta se dan luego de la tercera copa, a partir de la cual se observa un corrimiento del umbral de desinhibición. El vino habilita dentro de los rituales de interacción niveles crecientes de excitación mutua y de efervescencia colectiva (Collins, 2009) que se observan en diversas escenas de seducción y una mayor relajación de la glosa corporal.

\section{Apartado metodológico}

La metodología del artículo es cualitativa. Empleé la técnica de observación participante y entrevistas en profundidad con los/as clientes/as y el organizador de las catas. Ambas fuentes son utilizadas descriptivamente para llevar a cabo el análisis.

Asistí a las catas durante un año (2016-2017). Las catas se llevaban a cabo dos viernes por mes y tenían una duración promedio de cuatro horas - de las 20 horas a las 00 horas- . Durante el desarrollo de la investigación entrevisté al organizador de la cata en dos ocasiones de manera individual, al margen de las múltiples charlas informales que tuvimos. Asimismo, entrevisté a su asistente y en distintas oportunidades me senté junto a él durante el desarrollo de las catas. Ambos, el organizador y el asistente, estuvieron

aquí analizados concurren personas dentro de este grupo etario y son promocionados por sus organizadores, principalmente y/o exclusivamente, para un público específico de mayores de 35 ó 40 años.

${ }^{6}$ Retomo la caracterización y tipología de clase media en la Argentina que desarrolla Sautu (2016). La clase media comprende fracciones compuestas por ocupaciones que se desempeñan en el sector privado y en el sector público de la economía. Su rasgo común es que no se insertan en el poder económico y político, pero tampoco en el otro extremo de la estructura de clase. Los gerentes operativos, los profesionales, los propietarios y agentes de sector privado conforman la clase media junto con diversos niveles de la burocracia nacional, provincial y municipal (Sautu, 2016, p. 180). En este artículo abordo a personas adultas de sectores medios residentes en el Área Metropolitana de Buenos Aires, Argentina. 
siempre atentos a que yo me sintiera cómoda y me integraron en todo momento con los/as clientes/as habituales.

En las catas más numerosas concurrieron alrededor de 25 personas; en las más pequeñas, 15. Si bien el público se renueva de una cata a otra, hay alrededor de 10 clientes/as asiduos. De entre estos/estas, entrevisté de manera particular - al margen de las conversaciones que teníamos durante las degustaciones-, a cinco. Una de las entrevistadas, Micaela, era vecina, por lo que regresábamos juntas a nuestros hogares, caminando y hablando.

\section{Cuadro 1.}

\section{Personas entrevistadas ${ }^{7}$}

\begin{tabular}{|c|c|c|c|c|c|}
\hline Entrevistado/a & $\begin{array}{c}\text { Estado } \\
\text { Civil }\end{array}$ & Trabajo & $\begin{array}{c}\text { Máximo nivel de } \\
\text { instrucción } \\
\text { alcanzado y carrera }\end{array}$ & Hijas/os & Edad \\
\hline José Luis & Separado & $\begin{array}{l}\text { Puesto intermedio en relación de } \\
\text { dependencia en ámbito privado y } \\
\text { trabaja de forma independiente }\end{array}$ & $\begin{array}{c}\text { Universitario } \\
\text { Incompleto. Análisis } \\
\text { en sistemas }\end{array}$ & No & 43 \\
\hline Fernando & Divorciado & $\begin{array}{l}\text { Puesto jerárquico en relación de } \\
\text { dependencia en el ámbito } \\
\text { privado. Profesional }\end{array}$ & $\begin{array}{c}\text { Universitario } \\
\text { Completo. Ingeniería }\end{array}$ & Sí, dos & 50 \\
\hline Micaela & Divorciada & $\begin{array}{l}\text { Puesto administrativo. Trabaja en } \\
\text { relación de dependencia en el } \\
\text { ámbito público }\end{array}$ & $\begin{array}{c}\text { Terciario completo. } \\
\text { Magisterio nivel } \\
\text { primario e inicial }\end{array}$ & Sí, uno/a & 44 \\
\hline Aldana & $\begin{array}{l}\text { Soltera. } \\
\text { Nunca } \\
\text { convivió }\end{array}$ & $\begin{array}{c}\text { Trabaja como docente de forma } \\
\text { independiente }\end{array}$ & $\begin{array}{l}\text { Terciario completo. } \\
\text { Profesorado en } \\
\text { Educación Física }\end{array}$ & No & 50 \\
\hline Natalia & $\begin{array}{l}\text { Soltera. } \\
\text { Nunca } \\
\text { convivió }\end{array}$ & $\begin{array}{c}\text { Trabaja como profesional en el } \\
\text { ámbito público }\end{array}$ & $\begin{array}{c}\text { Universitario } \\
\text { completo. Ciencias } \\
\text { ambientales }\end{array}$ & No & 45 \\
\hline
\end{tabular}

Las entrevistas personales tuvieron guiones flexibles y duraron entre una hora y media y dos horas cada una. Éstas, a partir de la propuesta de Elena Achilli (2005), no

\footnotetext{
${ }^{7}$ Los nombres de las personas entrevistadas fueron modificados a fines de respetar el anonimato y la confidencialidad.
} 
comenzaban con preguntas predefinidas; al contrario, me interesaba permitirle al/la entrevistado/a que ponderase sobre las temáticas que quería explayarse. No obstante, algunos aspectos que eran de importancia para la investigación fueron abordados como ejes de entrevista y no como preguntas estructuradas: a) trayectorias de pareja, parejas más significativas, vínculos sexuales; b) la espacialidad, cómo y por qué comenzaron a concurrir a las catas, si iban a otros espacios de sociabilidad nocturna, qué buscaban y qué expectativas tenían — tipos de vínculos, expectativas sexuales y eróticas-; c) la soledad, cómo vivenciaban el no estar en pareja, y d) la corporalidad y seducción, cómo aparecía la corporalidad en las pautas de cortejo, cuáles eran los guiones de seducción, qué papel jugaba la edad, qué sujetos eran corporalmente deseables y cómo se presentaban ellos/as estéticamente frente a escenarios (Goffman, 1979) de cortejo, erotismo y encuentros eróticos y/o afectivos.

Todos estos ejes fueron atravesados por la dimensión afectiva: cómo se sentían ante el hecho de no estar en pareja, en las búsquedas y al momento del cortejo. Se consultó además sobre indicadores sociodemográficos, a saber, profesión, nivel de educación alcanzado, estilos de vida, gustos e intereses de clase que influyen directamente al momento de la búsqueda.

Por su parte, durante las observaciones tuve en cuenta distintos aspectos: a) la dimensión afectiva: los afectos que emergían durante las interacciones entre los/as clientes/as y de ellos/as con el organizador; b) el corporal y la seducción: la glosa corporal, los posibles acercamientos y distanciamientos entre las personas, y las situaciones y elementos que erotizaban a las mujeres y varones heterosexuales observados/as; c) la clase social: la hexis corporal, vestimenta, espacios de sociabilidad y comentarios que se realizaban.

El espacio de la cata de vino fue elegido a partir de distintos criterios. El primero se basa en el interés que genera el vino. El consumo "masivo" de vinos boutiques y la proliferación de bodegas comenzó a gestarse al comienzo del nuevo siglo. Tres dueños/as de vinerías que entrevisté durante el trabajo de campo me explicaron que las personas de sectores medios y altos de la Ciudad de Buenos Aires habían comenzado a refinar sus gustos y a volverse consumidores de las nuevas tendencias que aparecían dentro de este mercado. Años más tarde, las catas comenzaron a ser promocionadas 
como ámbitos de sociabilidad erótica-afectiva en diarios de circulación masiva de la Argentina; el diario Clarín (10 de mayo de 2015), por ejemplo, publicó una nota denominada "Levante entre copas: el vino, una nueva excusa para buscar pareja".

Asimismo, el vino trae consigo una variedad de consumos culturales propios de sectores de clase media urbanos. Existe hoy en día, en la Ciudad de Buenos Aires, una multiplicidad de vinerías en barrios de clase media que ofrecen eventos de catas a través de pizarras en la puerta de las vinotecas o de las redes sociales Facebook e Instagram.

La vinería observada es accesible para los sujetos que la frecuentan, tanto económica como geográficamente. Es decir, su entrada es de paga pero a un bajo costo dentro del poder adquisitivo de sus clientes/as y está ubicada en un barrio mayoritariamente de clase media y alta de la Ciudad de Buenos Aires, Argentina, donde ellos/as circulan.

\section{Coordenadas teóricas interaccionistas}

Me baso en una perspectiva de análisis interaccionista (Goffman, 1970, 1971, 1979; Collins, 2009). Para este tipo de abordaje, la co-presencia física deviene en encuentro cuando se transforma en interacción enfocada, con un foco de interacción común y de intensidad entre al menos dos personas (Collins, 2009). Para Goffman (1971, 1979), los encuentros son tipos de interacciones signadas por normas que sincronizan el proceso de obtener la atención del orador y de que este obtenga la de uno.

Las interacciones están cargadas de emociones. La energía emocional durante los rituales de interacción aumentará o disminuirá según haya sinergia o no de emociones, valores, memorias, acciones, estructuras y moralidades entre las partes (Collins, 2009). La posibilidad de que exista dicha sinergia depende de la pertenencia compartida a un sector de clase social común que habilite la experiencia de un universo compartido. De allí que la energía emocional genera sentimientos de membresía e, individualmente, confianza, alegría e iniciativa para la acción, entre otros. Asimismo, durante los rituales de interacción las personas buscan aumentar su propia energía emocional, si bien ésta se 
distribuye de forma desigual, según las posiciones relativas de poder y estatus que tengan los sujetos.

Algunos ejemplos de rituales de interacción que aparecen en la búsqueda de encuentros eróticos y/o afectivos y en las interacciones son una charla, una carcajada compartida, un beso y otras formas de seducción o cortejo. En estos rituales los individuos se sumergen corporalmente y se da una sincronización. En aquellos casos donde el decoro ritual se rompe, los sujetos sienten lo que Collins (2009) denomina una incomodidad moral.

Para la perspectiva interaccionista en la cual me baso, el ritual de interacción es un proceso corporal y posee una lectura del cuerpo fundamentada en los aportes de la teoría fenomenológica de Merleau-Ponty (1970). Para el autor, los cuerpos son productores de sentidos y no son pasivos. Las personas no solo tienen un cuerpo, sino que son en el mundo con el cuerpo. El mundo es entendido a través del cuerpo como experiencia física y como experiencia sensible atravesada y generadora de emociones (García Andrade y Sabido Ramos, 2014). Explica Collins (2009) que cuando los cuerpos humanos se reúnen en un mismo lugar ocurre una sintonización de la cual emergen diferentes emociones, como el recelo o el interés.

Los rituales son iniciados por la convergencia de cuerpos humanos en un mismo lugar. Las emociones que generan los rituales se expresan y visualizan a través de la glosa corporal (Goffman, 1979). Goffman explica que los individuos se expresan tanto por lo que dicen como por lo que emanan corporalmente. La energía emocional se observa en las posturas y movimientos corporales, en la mirada, la voz y la expresión facial (Collins, 2009), ejes que fueron indagados durante las observaciones. Estos aspectos se ven, por ejemplo, en un diálogo. Cuando las personas dialogan y tienen un foco de atención común, tienden a sincronizar sus movimientos corporales con el ritmo al que hablan; esto significa que la energía emocional aumenta. Se miran unos a otros y lo hacen siguiendo un patrón rítmico: miran el rostro del otro, se responden con microexpresiones. Hay fluidez en el habla y priman expresiones faciales de confianza y entusiasmo.

A partir de esta glosa corporal, en una determinada situación, en este caso las catas de vino, los individuos desarrollan corporalmente un "display de intenciones" (Goffman, 
1979, p. 30) que son interpretables y predecibles por el resto de las personas. En el trabajo de seducción, el cuerpo crea situaciones de intimidad o proximidad corporal (Simmel, 2014) que exceden las relaciones sexuales, como por ejemplo el baile.

En el display de intenciones, la presencia corporal de otras personas nos genera una impresión sensible (Simmel, 2014). La noción de impresión sensible o de proximidad sensible implica que en las interacciones cara a cara les atribuimos a los/as otros/as diversos sentidos de percepción, a partir de los cuales establecemos formas de relación (Simmel, 2014; Sabido Ramos, 2007). Desde este concepto es posible llevar a cabo un análisis sobre, por ejemplo, las emociones del asco y el desprecio que podemos experimentar en los momentos en los que nos encontramos con otros/as, aunque sean fugaces.

La percepción sobre el otro está atravesada por "modos somáticos de atención". Estos son "modos culturalmente elaborados de prestar atención a, y con, el propio cuerpo, en entornos que incluyen la presencia corporizada de otros" (Csordas, 1999 p. 87). Los modos somáticos de atención incluyen, además de la atención $a$ y con el propio cuerpo, la atención a los cuerpos de las otras personas. Percibimos y evaluamos, desde nuestra propia experiencia, los movimientos, la posición corporal, los gestos, los olores de los otros. Las formas de percibir, sobre qué es agradable y desagradable, no son naturales, sino que están definidas social y culturalmente. Dependen del habitus de los sujetos (Bourdieu, 1987), el cual implica "un sistema de esquemas adquiridos que funcionan en estado práctico como categorías de percepción y de apreciación o como principios clasificatorios al mismo tiempo que como principios organizadores de la acción" (Bourdieu, 1987, p. 26). Estos esquemas se combinan con las interacciones específicas que cada uno de los sujetos mantiene. Es decir, sumado al influjo cultural y sociohistórico, cada uno de nosotros cuenta con una trayectoria biográfica que hace variar nuestras prácticas y perspectivas. Ambos aspectos definen nuestras percepciones sensoriales y nuestros gustos; en otras palabras, las afinidades electivas (Bourdieu, 1998, p. 282) que nos unen con otras personas o cosas.

En este sentido, mi lectura del cuerpo es relacional. El cuerpo no es reductible a un aspecto anatómico, no es inerte, porque el sujeto y su cuerpo se van constituyendo en 
relación con quienes interactúan en determinado espacio-tiempo (Butler, 2002; Collins, 2009; Giddens, 1997; Grosz, 1994; Le Breton, 1995; Nancy, 2007; Turner, 1984).

\section{El aumento de la energía emocional: la tercera copa}

La vinoteca se encuentra en una esquina del barrio de Palermo de la Ciudad de Buenos Aires. Cuando una se acerca un viernes por la noche, alrededor de las 20 horas, se encuentra con un cartel que dice con letras de colores: "Hoy hay cata de vinos". Las catas son a veces dadas por un sommelier y otras por una sommelier.

En ese pequeño espacio hay botellas por doquier, todas de bodegas boutique, y una mesa con dos sillones donde se sientan las primeras personas que llegan. La vinoteca tiene dos pisos, el que da a la calle y un sótano donde tienen lugar las catas. El sótano está ambientado y preparado para las mismas. Se ingresa por una puerta de vidrio que da a un espacio iluminado con veladores de luces tenues pero cálidas, y decorado con barriles, antigüedades y objetos referidos al vino. Cuando se entra, las copas ya están sobre la mesa y hay paneras con galletas. El dueño del lugar y su asistente, un amigo del primero que lo ayuda en el armado de las catas, supervisan que todo esté en orden y les indican a las personas que llegan que se ubiquen donde más les guste.

El sótano tiene forma de romboide. Hay cuatro mesas con espacio para dos personas pero donde se pueden sentar hasta cuatro; dos sillones grandes que tienen al costado mesas ratonas, y sillas sueltas. Al fondo del sótano hay un pequeño estante con las botellas que serán catadas y en donde se encuentra de pie el/la sommelier que aguarda sonriente mientras los/as clientes/as se acomodan. Las botellas ya están abiertas y tienen colocado el pico correspondiente para servirse.

Las personas van bajando, las que concurren solas se sientan en los sillones o en algunas de las sillas sueltas. Las parejas eligen las mesas de dos y los grupos de amigos/as se amontonan en las otras mesas de dos. 
El sótano es pequeño pero confortable. Posee un aire acondicionado frío/calor que el organizador va programando según las necesidades de sus clientes/as. Antes de comenzar la cata siempre nos pregunta: “¿Está bien el aire así? ¿Quieren que lo baje, lo suba? Díganme, por favor”. El escenario de interacción puede ser definido, según mi experiencia, como un lugar cálido y confortable.

Para tener una visión panorámica de las interacciones que se desarrollan en ese escenario solía sentarme en la última mesa, cerca de la puerta, la más alejada de donde estaba el/la sommelier. Podría decirse, haciendo una analogía con el aula de una escuela, que me sentaba en el "último banco". La mesa era cuadrada y tenía tres sillas. Elegí esa mesa como lugar de observación desde mi primera cata.

En la primera degustación a la cual asistí, el asistente del organizador de las catas, un varón joven a quien lo había entrevistado una hora antes, se sentó conmigo. Sus amigos/as, clientes/as frecuentes de las catas, se sumaron a nuestra mesa. Como eran varios/as unieron la mesa de al lado. Para cuando la cata había comenzado estábamos sentados alrededor de ambas mesas diez personas. Éramos ocho varones y dos mujeres.

Durante esa cata, el asistente ofició de informante clave en todo momento. Cuando nos sirvieron la primera copa de vino, él me miró y me dijo "vas ver que en la tercera copa de vino todo se distiende". Esta máxima fue registrada por mí en cada una de las observaciones que desarrollé durante un año y reafirmada a partir de las entrevistas en profundidad que realicé a clientes/as de este espacio.

Desde la lectura de Collins (2009) sobre el consumo de tabaco, las catas de vino pueden ser analizadas como rituales de estilo de vida. Por un lado, el consumo de vinos boutiques en barrios pudientes de la ciudad es una actividad desde la cual se expresa un cierto estatus. Por el otro, la ingesta de vinos genera un aumento de la energía emocional grupal, produce una consonancia mutua entre la atención y la emoción de los/as participantes.

En la tercera copa de vino se aprecia, en las distintas catas, la emergencia de situaciones de sociabilidad signadas por una mayor desinhibición. La gente comienza a hablar entre sí, se diluye la figura de autoridad del/a sommelier. El silencio que primaba al comienzo 
es reemplazado por el bullicio y las risas, ante lo cual el/la sommelier y el organizador piden, amablemente, silencio. Circulan bromas entre los/as usuarios/as, hasta entonces desconocidos/as entre sí. La tercera copa puede ser analizada como un ritual de interacción que da forma a una experiencia corporal y emocional concreta, generando efervescencia colectiva (Collins, 2009) que habilita la desinhibición corporal y una sociabilidad más relajada.

En una de las catas, luego de la tercera copa de vino, registré una escena donde se observa, basándome en la lectura de Elizalde y Felitti (2015), a las mujeres no sólo como consumidoras sino también como agentes activas al momento de manifestar sus deseos. En uno de los costados del sótano, había una mesa con un grupo de cuatro amigas. Ellas comenzaron a mirar a dos varones que se encontraban sentados en la mesa trasera. Mientras los miraban, comentaban y se reían. Ellos eran conscientes de esto y comenzó a tener lugar el juego de miradas cruzadas. En un momento de la noche, ante una pregunta del sommelier sobre el sabor de un vino, una de las mujeres se dio vuelta y les dijo a los varones de la mesa trasera, con tono de voz suave y una sonrisa: "A ver, chicos, ¿qué tienen para decir?”. Todos/as nos reímos de la situación, aunque expectantes de la respuesta masculina. Dado que ninguno de los varones respondió de forma rápida, otro varón de mayor edad sentado en otra parte del escenario les gritó: "No arruguen, muchachos", haciendo referencia a que la mujer estaba intentando entrar en contacto con uno de ellos y que, en cuanto eran evaluados como varones heterosexuales, debían responder al deseo femenino. Dentro de los postulados de masculinidad hegemónica (Connell, 1995) se espera que los varones estén siempre disponibles para lo erótico y sexual. Si un varón se pone nervioso ante el deseo erótico femenino o lo rechaza, su performance de seducción masculina heterosexual será puesta en discusión.

Estas situaciones son rituales naturales de interacción en cuanto generan un foco de atención compartido y consonancia emocional sin la necesidad de protocolos formalmente estereotipados o rituales formales regidos por procedimientos ceremoniales (Collins, 2009, p. 75). En las situaciones aquí descriptas la energía emocional aumenta de forma espontánea. La tercera copa de vino simboliza el pasaje de un estado de "sobriedad" a uno de "desinhibición". Esta bebida aumenta la energía grupal, lo que se observa en las risas y el destendimiento corporal. 
Al comienzo de las catas — sobriedad—, los cuerpos tienden a la quietud, cada uno está sentado en su silla, en silencio o hablando bajo; en el segundo estado — desinhibiciónlas personas hablan fuerte, se mueven, cambian de lugar. En este estadio se genera más confianza y alegría entre los participantes de la cata, como así también sentimientos de membresía. Esto se visualiza en que se ríen de los chistes y hay una correspondencia entre los temas de interés que comienzan a circular, entre ellos los comentarios referidos a temas sexuales. Es decir, la energía emocional aumenta.

En el estadio de inhibición la glosa corporal se distiende. Algunas de las mujeres que estaban sentadas en silencio y mantenían posturas rígidas, luego de la tercera copa se sueltan el cabello y empiezan a tocárselo. Comienzan a hablar con otros varones. Aparece de forma más evidente una lógica de seducción signada por el cruce de miradas entre varones y mujeres sentados/as en distintas partes del escenario. Las miradas son un guion recurrente de seducción y de cortejo, de display de intenciones que apelan a la idea simmeliana (Simmel, 2003) de la coquetería. Implican, desde el silencio de la palabra, un quizás más tarde hablemos o un quizás me gustes. Ese quizás, en cuanto somos cuerpos vivos, que afectamos y somos afectados, genera efectos y deseos entre las personas que observan y que son observadas (Grosz, 1994; Frigerio, 2006).

Durante las catas se visualiza que las mujeres expresan de manera activa sus deseos y desarrollan distintas performances de seducción. Los actos de seducción femeninamirar a quienes les parecen atractivos, tocarse el pelo o hablarles delante de todos con un tono suave y simpático- son, en términos de Bianciotti (2013), "performances de seducción medidas (sutiles)". Según la autora, así las mujeres se muestran sexys, simpáticas y sensuales, pero "sin los excesos adjudicados a la figura del gato (exhibicionismo excesivo del cuerpo y la seducción exacerbada) o la puta (excesiva cantidad de compañeros eróticos)" (Bianciotti, 2013, p. 608).

Las mujeres que concurren a las catas son, tal como presenté en la Introducción, mujeres de sectores medios que trabajan a jornada completa en relación de dependencia y que poseen títulos universitarios o terciarios. Su modo de vestir cuando concurren a las catas posee continuidades con la vestimenta que utilizan en cualquier otro ámbito de sociabilidad, esto es, visten con jeans, camisas o blusas. Llevan zapatos con o sin taco y 
no usan ropa escotada o polleras cortas. Su forma de vestir se aleja de cualquier tipo de exhibición corporal. Si bien están maquilladas, su forma de maquillarse es sutil y con colores sobrios: usan base, se delinean los ojos y utilizan labiales claros. Combinan seducción con elegancia y distinción propias de su habitus de clase. Como explica Bianciotti, las formas de seducción medidas (o sutiles) se basan en una estilización elegante y la exhibición moderada del cuerpo. Así las mujeres buscan lograr una belleza que se pretende natural, en contraposición al "gato". Muestran un aspecto personal sexy y fino a la vez (Bianciotti, 2013, p. 613).

Luego de catar los vinos, alrededor de cinco copas por noche, el dueño trae empanadas, dos por persona, y picadas de fiambres para todos/as, una por mesa. Como algunos/as no están en ninguna mesa, se sientan o acercan a quienes están sentados. Esto favorece el diálogo y el intercambio. Este es el momento en el que quienes cruzaron miradas a lo largo del evento se aproximan corporalmente. Los varones, con la excusa de que van a buscar algo para comer, se acercan a la mujer que les pareció atractiva. Esta escena que observo en distintas catas también es relatada por Aldana (50 años), clienta frecuente de la cata, durante la entrevista que le realicé. Luego de mirarse con un varón más joven durante toda la noche, tuvieron su primer acercamiento verbal en el momento de la picada.

\section{E: ¿Cómo fue el acercamiento?}

Aldana: En la cata el pibe no paraba de mirarme, yo también obvio. Comimos algo ahí en la cata y ahí hablamos un poco. Después de la cata fuimos todos a comer porque viste que ahí es una picadita, entonces vamos todos a comer a otro lado o pedimos empanadas y nos quedamos ahí. El chico no paraba de tirarme los galgos, no paró en toda la noche, estaba a mil. Tendría 25 años. Y terminamos de cenar y me quedé a dormir en la casa del pibe. Era hermoso, un bombón el chico (entrevista a Aldana, 50 años).

La forma de cortejo y seducción a partir del juego de miradas, en el caso de Aldana como en otras escenas que observé, aunque no implique la generación o la búsqueda de un vínculo de pareja, se da en términos monógamos. Es decir, si bien en el contexto de modernidad tardía prevalecen los vínculos fugaces y las trayectorias eróticas-afectivas zigzagueantes y heterogéneas, distinto al modelo de familiar nuclear y de amor 
predominante décadas antes (Ariño, 2007), el modo de cortejo se continúa dando exclusivamente entre dos personas. En los casos donde hay energía emocional entre dos personas se observa que no cortejan, además, explícitamente con otras personas en ese espacio a lo largo de la noche. El formato del cortejo se organiza dentro de un guión monogámico. Sin embargo, subrayo que es "en ese espacio" porque las personas durante el evento utilizan sus celulares y chatean con otros/as con los/as cuales, quizás, desde lo virtual, estén sociabilizando erótica y/o afectivamente o pautando encuentros de este tipo.

Los celulares son actantes presentes en los eventos de las catas de vino. Observo durante mi trabajo de campo que los/as usuarios/as prenden sus celulares en diferentes momentos de la noche, escriben o revisan los perfiles de sus redes sociales. Cuando ya se encuentran más desinhibidos/as y relajados/as, se sacan selfies con sus amigos/as o fotografían a la banda de música que toca al final del evento. Asimismo, los celulares son utilizados cuando hay sinergia emocional entre las personas. Los/as clientes/as intercambian sus números telefónicos como forma de establecer un contacto, ya sea con vistas a una posible amistad o en una escena de seducción.

La energía emocional entre dos personas se incrementa si ambos se perciben como agradables. Esto se genera a partir de sus modos de atención (Csordas, 1999) que implican la forma de evaluar y percibir al otro (por sus olores, gestos, cuerpo). Un rasgo estético que vuelve a alguien deseable en las catas de vino es su olor. Observo que el olor del escenario de la cata está marcado por el aroma al vino y las fragancias de perfumes importados que utilizan sus usuarios/as.

El perfume y el buen aroma aparecen como aspectos ponderados por uno de los entrevistados al momento de tener una cita.

E: ¿Cómo te preparas vos para una cita?

José Luis: Yo primero me tengo que bañar. Entre que te bañás, te perfumás, te pones gel para estar lo mejor, lo mejor pituco posible. No para impresionar sino para que te sientas cómodo y tener perfume adentro del auto. El coche tenga buen aroma. Yo lavo al coche una vez por semana. Siempre los domingos va a lavadero el coche (Entrevista a José Luis, 43 años). 
El perfumarse es una forma de distinción en términos de clase social y una estrategia para generarles a las otras personas una percepción sensorial agradable sobre sí mismos y de demostrar la pertenencia a un cierto estrato social y no a otro. Oler bien es una de las formas que poseemos para no producirle a los otros asco o desprecio (Sabido Ramos, 2007; Simmel, 2003) y aumentar nuestro capital erótico (Hakim, 2012) para mostrarnos más deseables ante un determinado público.

Los olores aceptables o no dependen del círculo social en el cual estamos insertos. Es decir, el sentido del olfato está construido socialmente. Los olores para Synnott son un arma de defensa para menospreciar a los demás (Synnott, 2003, p. 443); sirven para legitimar desigualdades de clase y raciales y para imponerle a una población determinada una identidad moral negativa.

Dentro de los rituales de interacción de las catas de vino están los recitales acústicos de grupos musicales. Las canciones que interpretan apuntan a un público de sectores medios. Los temas son, principalmente, en inglés, de estilo soul, jazz y rock, y sus letras poseen contenido amoroso. Estas canciones versan sobre historias de pareja, peleas amorosas, la búsqueda del amor y el dolor que genera amar. Cuando tocan las bandas, el organizador apaga las luces y solo quedan prendidos unos veladores de color anaranjado con luces tenues. Cuando el grupo musical se presenta las personas hacen silencio. Para este momento todos/as ya hemos tomado cinco copas de vino y más. Las miradas de algunos/as espectadores/as, idas y con brillo en los ojos, parecen estar conectadas con recuerdos u otras sensaciones que les genera la música, el alcohol y la ambientación del espacio. Aquellas personas que van en pareja se dan la mano y se besan. El ideal regulatorio romántico, por las letras de las canciones y los movimientos corporales de los/as clientes/as, impregna el escenario. Entiendo por este ideal a la idealización del sujeto amado, la propuesta de un proyecto compartido que perdure en el tiempo, la promesa de la fidelidad y también elementos del amor agápico, como por ejemplo la entrega total (Marentes, Palumbo y Boy, 2016).

En contraposición a este discurso más romántico, en una de las catas un dúo tocó la canción de Jimi Hendrix denominada "Foxy Lady" (Chica Zorra), en la cual el modelo de feminidad se basa en la seducción. Cuando la cantante la presentó dijo: "Dedicado a 
todas las chicas zorras". Esto incrementó la energía emocional entre las mujeres. Hubo chiflidos de aprobación y risas entre ellas, una erotización menos sutil y más explícita. La cantante apeló a un corrimiento dentro del sistema estético-erótico-moral, en términos de Bianciotti (2013), de aquello considerado como una feminidad medida. La aprobación por parte de las otras mujeres de este deslizamiento, aunque sea a nivel discursivo, tensiona las tecnologías de género (De Lauretis, 1996) y del yo (Foucault, 1990) a partir de las cuales se crea un ideal regulatorio de sujeción y subjetivación de lo femenino en términos de autocontrol. Se visualizan otros deseos.

\section{Conclusiones}

En este artículo describí y analicé cómo actúa la energía emocional en interacciones que se desarrollan en catas de vino. Para tal fin tuve en cuenta aspectos como las pautas de cortejo y seducción, los modos somáticos de atención, la energía emocional y los afectos, las corporalidades y los escenarios de interacción.

Respecto al aumento de la energía emocional describí diferentes escenas, entre ellas, el juego de miradas con contenido erótico que aparece entre los/as clientes/as a partir de la tercera copa de vino, entendida como el pasaje del estado de "sobriedad" al de “desinhibición”. Esta desinhibición nunca es total, por el contrario, opera dentro de fronteras de lo esperable, tanto para varones como para mujeres. Se observa que durante las catas, las mujeres son agentes activas en la seducción, siempre y cuando lleven a cabo performances de seducción medidas (sutiles), en términos de Biancotti. Quienes desborden ese umbral serán vistas como mujeres "no respetables". Por su parte, se espera de los varones ciertos comportamientos propios de la masculinidad hegemónica. Por ejemplo, en la escena que observé, cuando una de las mujeres interpeló directamente a dos varones, el resto del público de la cata depositó en ellos una expectativa de pronta respuesta. Quien enunció imperativamente que debían responder era un varón mayor a ellos. Se espera de la masculinidad heterosexual que esté permanentemente dispuesta para el terreno de lo erótico y sexual. Caso contrario, su 
performance de seducción será cuestionada ante la mirada de los otros y especialmente de varones heterosexuales mayores.

Otro registro donde el vino emerge como un desinhibidor es en los cuerpos de los/as clientes/as de las catas. Dentro de ciertos marcos, se aprecia un mayor contacto corporal, juego de miradas y relajación de la glosa corporal.

Las catas de vino surgen, tal como expliqué en la introducción, debido a un aumento del mercado de vino dentro de los sectores medios y altos urbanos, en este caso de la Ciudad de Buenos Aires. Este interés común llevó a la emergencia de las catas de vino como un espacio donde poder degustar diferentes vinos y aprender de ellos. Desde este inicio, se observa que hoy es un espacio de sociabilidad erótica y/o afectiva — bien sea para generar amistades, aumentar la auto-estima a partir del contacto con pares o para conocer personas con quienes tener relaciones eróticas-afectivas.

El análisis de la energía emocional permite examinar, para un momento y espacio dado, cuáles son las performance de seducción aceptados y cuáles no, tanto por mujeres como por varones, cómo opera la masculinidad hegemónica y cuáles atributos vuelven a alguien deseable. En pocas palabras, a través de un análisis de las fluctuaciones de la energía emocional podemos visualizar la sinergia y las emociones que atraviesan la interacción así como las relaciones de estatus y poder que existen dentro de ellas.

\section{Referencias bibliográficas}

Achilli, E. (2005). Investigar en Antropología social. Los desafíos de transmitir un oficio. Rosario: Laborde Editor.

Agustín, L. (2005). La industria del sexo, los migrantes y la familia europea. Cadernos Pagu, 25, 107-128. doi: http://dx.doi.org/10.1590/S0104-83332005000200005

Ariño, M. (2007). Familias tradicionales, nuevas familias. En S. Torrado (Comp.), Población y bienestar en la Argentina del primero al segundo Centenario. Una historia social del siglo XX. Tomo II (pp. 255 - 284). Buenos Aires: Edhasa. 
Bianciotti, M.C. (2013). Género, erotismo y subjetividad: formas de clasificación estético-erótico-morales jerarquizantes entre mujeres jóvenes heterosexuales. RBSERevista Brasileira de Sociologia da Emoção, 12(35), 594-616.

Blumer, M., Ansara, G. y Watson, C. (2013). Cisgenderism in family therapy: how everyday clinical practices can delegitimize people's gender self-sesignations. Journal of Family Psychotherapy, 24(4), 267-285. doi: https://doi.org/10.1080/08975353.2013.849551

Bourdieu, P. (1987). Cosas dichas. México: Gedisa.

Bourdieu, P. (1997). Capital cultural, escuela y espacio social. México: Siglo XXI.

Bourdieu, P. (1998). La Distinción. Criterios y bases sociales del gusto. Madrid: Taurus.

Bourdieu, P. y Wacquant, L. (2005). Una invitación a la sociología reflexiva. Buenos Aires: Siglo XXI.

Butler, J. (2002). Cuerpos que importan. Sobre los límites materiales y discursivos del "sexo”. Buenos Aires: Paidós.

Collins, R. (2009). Cadenas de rituales de interacción. Barcelona: Anthropos, UAMAzcapotzalco, UNAM-FCPY, Editorial Universidad Nacional de Colombia.

Connell, R. (1995). Masculinities. Berkeley: University of California Press.

Csordas, T. (1999). Embodiment and Cultural Phenomenology. En G. Weiss y H. Haber (Eds.), Perspectives on Embodiment. The Intersections of Nature and Culture (pp. 143162). Routledge: Nueva York.

De Lauretis, T. (1996). La tecnología del género. Mora. Revista del Área Interdisciplinaria de Estudios de la Mujer, 2, 6-34. 
Dirección General de Estadística y Censos. Gobierno de la Ciudad de Buenos Aires (2014). Matrimonios en la Ciudad de Buenos Aires. Años 1990-2013. Ciudad de Buenos Aires: Dirección General de Estadística y Censos.

Elizalde, S. y Felitti, K. (2015). "Vení a sacar a la perra que hay en vos": pedagogías de la seducción, mercado y nuevos retos para los feminismos. Revista Interdisciplinaria de Estudios de Género de El Colegio de México, 1(2), 1-32. http://dx.doi.org/10.24201/eg.v1i2.28

Foucault, M. (1990). Tecnologías del yo. Barcelona: Paidós.

Frigerio, G., y Diker. G. (2006). Educar: figuras y efectos del amor. Buenos Aires: Del Estante Editorial.

García Andrade, A. y Sabido Ramos, O. (2014). Cuerpo y afectividad en la sociedad contemporánea. Algunas rutas del amor y la experiencia sensible en ciencias sociales. Ciudad de México: Biblioteca de Ciencias Sociales y Humanidades, UAMAzcapotzalco.

Giddens, A. (1997). Modernidad e identidad del yo. El yo y la sociedad en la época contemporánea. Barcelona: Ediciones Península.

Goffman, E. (1970). Ritual de la interacción. Buenos Aires: Tiempo Contemporáneo.

Goffman, E. (1971). La presentación de la persona en la vida cotidiana. Buenos Aires: Amorrortu.

Goffman, E. (1979). Relaciones en público. Madrid: Alianza.

Gregori, M.F. (2011). Mercado erótico: notas conceituais e etnográficas. En A. Piscitelli, G. Oliveira de Assis, y J.M. Nieto Olivar (Orgs.), Gênero, sexo, amor e dinheiro: mobilidades transnacionais envolvendo o Brasil (pp. 461- 490). Campinas: Pagu / Núcleo de Estudos de Gênero UNICAMP. 
Grosz, E. (1994). Volatile Bodies. Bloomington: Indiana University Press.

Guerra, P. (2016). Dilemas éticos en el mercado: un análisis desde la economía solidaria con aplicación en los mercados del sexo. Otra economía, 10(18), 91-105.

Haack, K., y Falcke, D. (2014). Love and Marital Quality in Romantic Relationships Mediated and Non-Mediated by Internet. Paidéia (Ribeirão Preto), 24(57), 105-113. doi: http://dx.doi.org/10.1590/1982-43272457201413

Hakim, C. (2012). Capital erótico: El poder de fascinar a los demás. Madrid: Debate.

Heineman, J.; Macfarlane, R.; y Brents, B. (2012). Sex Industry and Sex Workers in Nevada. En D. Shalin (Ed.), The Social Health of Nevada: Leading Indicators and Quality of Life in the Silver State (pp. 1-26). Nevada: UNLV: Center for Democratic Culture Publications. Disponible en http://cdclv.unlv.edu/healthnv_2012/sexindustry.pdf

Hochschild, A. (1983). The managed heart: commercialization of human feeling. Berkeley: University of California Press.

Hochschild, A. (2012). The outsourced self. intimate life in market times. New York: Metropolitan Books.

Illouz, E. (2007). Intimidades congeladas. Las emociones del capitalismo Buenos Aires: Katz Editores.

Illouz, E. (2009). El consumo de la utopía romántica. El amor y las contradicciones culturales del capitalismo. Buenos Aires: Katz Editores.

Illouz, E. (2012). Por qué duele el amor. Una explicación sociológica. Buenos Aires: Katz. 
Le Breton, A. (1995). Antropología del cuerpo y la modernidad. Buenos Aires: Nueva Visión.

Lipovetsky, G. (2000). La era del vacío. Ensayos sobre el individualismo contemporáneo. Barcelona: Anagrama.

Marentes, M., Palumbo, M., y Boy, M. (2015). "Me clavó el visto": los jóvenes y las esperas en el amor a partir de las nuevas tecnologías. Astrolabio. Nueva Época, 17, 307330.

Merleau-Ponty, M. (1970). Fenomenología de la percepción. México: Fondo de Cultura Económica.

Nancy, J. (2007). 58 indicios sobre el cuerpo. Extensión del alma. Buenos Aires: Editorial La Cebra.

Paiva, V. (2006). Analisando cenas e sexualidades: a promoção da saúde na perspectiva dos direitos humanos. En C. Cáceres, G. Careaga, T. Frasca y M. Pecheny (Eds.), Sexualidad, estigma y derechos humanos: desafíos para el acceso a la salud en América Latina (pp. 23- 52). Lima: FASPA/UPCH.

Piscitelli, A. (2009). Tránsitos: circulación de brasileñas en el ámbito de la transnacionalización de los mercados sexual y matrimonial. Horizonte Antropológico, 15(31), 101-136. doi: http://dx.doi.org/10.1590/S0104-71832009000100005

Piscitelli, A., Oliveira, G., y Nieto Olivar, J.M. (2011). Gênero, sexo, amor e dinheiro: mobilidades transnacionais envolvendo o Brasil. Campinas: Pagu / Núcleo de Estudos de Gênero UNICAMP.

Pruitt, D. (1995). For love and money: romance tourism in Jamaica. Annals of Tourism Research, 22(2), 422-440. doi: https://doi.org/10.1016/0160-7383(94)00084-0 
Sabido Ramos, O. (2007). El sentir de los sentidos y las emociones en la sociología de Georg Simmel. En O. Sabido Ramos (Coord.), Georg Simmel. Una revisión contemporánea (pp. 211-230). México: Anthropos, UAM Azcapotzalco.

Satz, D. (2015). Por qué algunas cosas no deberían estar en venta. Los límites morales del mercado. Buenos Aires: Siglo XXI.

Sautu, R. (2016). La formación y la actualidad de la clase media argentina. En G. Kessler (Comp.), La Sociedad argentina hoy. Radiografía de una nueva estructura (pp. 163- 184) Buenos Aires: Siglo XXI.

Serano, J. (2016). Whipping girl: A transsexual woman on sexism and the scapegoating of femininity. Berkeley: Seal Press.

Silva, A., y Blanchette, T. (2005). "Nossa Senhora da Help": sexo, turismo e deslocamento transnacional em Copacabana. Cadernos Pagu, 25, 249-280. doi: http://dx.doi.org/10.1590/S0104-83332005000200010

Simmel, G. (2003). Cuestiones fundamentales de sociología. Barcelona: Gedisa.

Simmel, G. (2014). Sociología. Estudios sobre las formas de socialización. Buenos Aires: Espasa Calpe.

Synnott, A. (2003). Sociología del olor. Revista Mexicana de Sociología, 65(2), 431464.

Torrado, S. (2007). Población y bienestar en la Argentina del primero al segundo Centenario. Una historia social del siglo XX. Buenos Aires: EDHASA.

Turner, B. (1984). The Body and Society. New York: Basil Blackwell. 


\section{Fuentes documentales}

Pace Muñoz, Fernando (10 de mayo de 2015). Levante entre copas: el vino una nueva excusa para buscar pareja. Clarín. Recuperado de http://www.clarin.com/sociedad/levante-vino-catas-degustaciones-gourmet-tendenciasolos_y_solas-conquista_0_1354664580.html

\section{Sobre la autora}

Mariana Palumbo es doctoranda en ciencias sociales por la Universidad de Buenos Aires, magister en investigación en ciencias sociales y socióloga por la misma universidad. Ha realizado dos estancias doctorales en la Universidad Nacional Autónoma de México. Entre sus áreas de interés, destacan: sexualidades, género y afectividades. Entre sus publicaciones más recientes se encuentran "Los estudios sobre sexualidad en la transición democrática argentina", en F. Blanco, M. Pecheny y J. Pierce, Politicas del amor: derechos sexuales y escrituras disidentes en el Cono Sur. Santiago de Chile: Cuarto Propio (2018, en coautoría); "Experiencias de amor y violencia”, en Estudos Feministas, 25 (3) 530 (2017), y el libro Pensar(nos) desde adentro: representaciones sociales y experiencias de género. San Martín: UNSAM Edita (2017). 